\title{
«ЭКЗИСТЕНЦИАЛЬНАЯ СОЦИАЛЬНАЯ ОНТОЛОГИЯ»: ПРОЕКТ М.Н. ВЕРНИКОВА В КОНТЕКСТЕ АНТРОПО-ОНТОЛОГИЧЕСКОГО ПОВОРОТА В СОВРЕМЕННОЙ УКРАИНСКОЙ ФИЛОСОФИИ
}

\section{И.В. Голубович}

Настоящая публикация является данью благодарной памяти основателю философского факультета в Одесском национальном университете имени И.И. Мечникова, профессору Марату Николаевичу Верникову (1934-2011). Коллеги, друзья, ученики знали его как замечательного организатора науки, бессменного заведующего кафедрой культурологии ОНУ, создателя журнала «Філософські пошуки», председателя специализированного ученого совета по защите докторских и кандидатских диссертаций, историка философии, специалиста по истории Львовско-Варшавской школы, реконструировавшего творческое наследие одного из представителей данной школы Степана Балея (см.: [2]).

За многообразием этих направлений плодотворной деятельности несколько в тени остаются собственные оригинальные идеи философа. В 2012 году одесские и львовские коллеги М.Н. Верникова подготовили сборник «Посвящения Марату» (см.: [12]). Одним из лейтмотивов, звучащих во многих публикациях, было то, что Марат Николаевич последовательно и принципиально отстаивал и активно пропагандировал идеи Львовско-Варшавской школы, с огромным энтузиазмом, самоотдачей и подлинным самопожертвованием вводил в научный отечественный оборот наследие польско-украинского мыслителя Степана 
Балея. При этом о своих собственных теоретических подходах он говорил с негромкой интонацией, выражая их в публикациях в «Філософських пошуках», в дискуссиях с коллегами и учениками. Философ предлагал не сухую, абстрактную, универсальную мыслительную конструкцию, а собственный образ жизни, этос и праксис. Его уроки, как это часто бывает, мы осваиваем с задержкой, с зазором, с необратимым опозданием. Однако сам способ бытия философии в мире дает нам обнадеживающую перспективу - вести диалог вне времени или в особом модусе времени philosophia perennis.

Современная философия и гуманитарное знание находятся под знаком самых различных «поворотов» - лингвистического, антропологического, онтологического и т.д. Специфику отечественной философии, которая также развивается под влиянием этих тенденций, сегодня во многом определяет взаимодействие антропологической и онтологической составляющей. Один из ярких примеров такого взаимопереплетения - проект «экзистенциальной социальной онтологии», предложенный М.Н. Верниковым. Обращение к данному проекту и творческое развитие заложенного в «экзистенциальной социальной онтологии» потенциала представляется нам чрезвычайно актуальным.

В современной украинской философии активно разрабатывается проблематика, связанная с осмыслением «новой онтологии», «социальной онтологии», «антропологического поворота». Развиваются идеи Киевской школы («Киевской мировоззренческо-антропологической школы»), которую в исследовательской и справочной литературе называют «онтологической» или «философско-антропологической» (В.И. Шинкарук, В.П. Иванов, В.Г. Табачковский, С.Б. Крымский, В.А. Малахов, Е.К. Быстрицкий, С.В.Пролеев и др.) (см., в частности: $[10,11,17])$.

Для нас особенно важно новое содержательное наполнение в рамках данной традиции понятий «социальная онтология», «новая онтология», «онтология без онтологизма», «постонтология», акцентирование человекомерности и человекоцентричности онтологического измерения социокультурного мира.

Принципиальная значимость «новоонтологической» переориентации заключается в смещении смыслового акцента на практически-духовную деятельность индивида, опыт субъективного освоения мира, воплощенного, прежде всего, в конкретности «жизненного пути», в неповторимости «стратегий и траекторий жизни». Это неизбежно провоцирует также смещение смыслового поля от «родовой всеобщности» человека к «индивидуально-экзистенциальной тотальности», темати- 
зирует индивидуально-личностные проявления человеческого бытия.

Отечественная специфика отмеченных нами «онтологического» и «антропологического» поворотов заключается в том, что они изначально осуществлялись как насыщение марксизма феноменологическим и экзистенциалистским содержанием («красный экзистенциализм»), а затем реализовывались и как феноменологически-экзистенциалистское «преодоление» марксизма в качестве господствующей объяснительной модели. Этот путь прошли и российские философы (П.П. Гайденко, М.К. Мамардашвили, Н.В. Мотрошилова, Э.Ю. Соловьев и др.).

«Онтологический поворот» совершался, прежде всего, по отношению к проблематике человека. Постулировалась необходимость преодоления монополии субъект-объектного описания человека, деятельностной парадигмы в целом. Было предложено рассматривать человеческое существование как «личностное бытие в мире» во всей полноте своего «здесь-и-теперь» существования. Не «субъект-объектность», а «человекомирность», которая все более продумывается в режиме «человекомерности».

Об этом писал, в частности, С.Л. Рубинштейн в работе «Человек и мир», в экзистенциально-онтологическом ключе переосмысливая марксизм, так же как и представители «Киевской школы», основанной В.И. Шинкаруком. «Мир» предполагает в качестве своего ядра «мир», соотносительный с человеком, в связи с этим «историчность» этого мира должна быть раскрыта сквозь призму специфических «конкретноисторических способов существования человека» (как частных «исторических онтологий») (см.: [15]). Онтологический статус обретают такие характеристики как «положение человека в мире», «ситуация человека» - прежде всего, конкретно-историческая и уникально-биографическая.

Вводится и онтологическое понимание культуры как способа человеческого бытия, само социокультурное бытие рассматривается как специфически человеческое бытие. С.В.Пролеев в этом контексте говорит об «онтологических модальностях человеческого бытия», среди которых важнейшими являются социальность, культурность, материальность, предметность (см.: [14, с. 5]). Эти и другие «онтологические модальности» становятся одновременно основными презумпциями «социальной онтологии».

В рамках «новоонтологической» рефлексии категория «бытие» трансформируется в категорию «жизнь», не утрачивая бытийственного содержания, а «жизнь», в свою очередь, предстает как само- 
осуществление индивида в человеческом мире, в «жизненном миpe», в Lebenswelt (эту трансформацию детально проанализировал В.П. Иванов (см.: [9])). Если «бытие» в новоонтологической установке становится Lebenswelt, это означает, что на первый план выходит смысловое измерение.

«Мир, светящийся смыслом» - такова основная характеристика Lebenswelt, на что обращал внимание А. Шюц (см.: [20]). «Смысловое свечение» не приходит извне, не эманирует из внешнего источника, запредельного человеческому миру. Оно - результат жизненного, человеческого, биографического опыта смыслоконституирования. В связи с этим концепт «опыт» также преобразуется, «онтологизируется», в данной установке речь идет об «историчности»и «фактичности», «життєсвітності» опыта (см. об этом глубокое исследование М.А. Минакова [8, с. 292-324]).

«Новая онтология» оказывается общим концептуальным срезом, который позволяет не только преодолеть субъект-объектную дихотомию, но и продумать пути возможного бытийственного объединения субъекта и объекта как «конкретного всеединства», как «трансцендентного в имманентном», как «найимманентнейшего в трансцендентном». Говоря об этом, современный украинский философ Г.Е. Аляев опирается на опыт С.Л. Франка, еще в 10-е годы ХХ века употреблявшего термин «новая онтология» и разрабатывавшего основы «социальной онтологии» (см.: [1, с. 9, 90]).

В.А. Малахов, размышляя о «постонтологии» - концепте, близкому к «новой онтологии», предлагает различать в отношении специфики человеческого бытия «онтологию снизу» и «онтологию сверху». «Онтология снизу» сводит человеческое бытие к тому, из чего человек растет - к его родовым корням, его почве и крови. «Онтология сверху» - то, до чего человек дорастает, дорастает, имея это изначально. В его модели во втором случае речь идет и о любви, вере, страдании, подлинном диалоге и подлинном молчании (см.: [7]). Так, например, исповедь В.А. Малахов называет «бытийно заряженным словом» и представляет его как «онтолого-диалогический аспект любой человеческой самореализации».

В рамках такого понимания онтологии предпринимается и иное позиционирование «Я». Европейская традиция философского рационализма вводит в теоретический оборот представление о «трансцендентальном субъекте» и «трансцендентальном Я», предлагая различные варианты их понимания и обоснования (см. об этом, в частности, исследование Я.А. Слинина: [16]). И. Кант не только осуществляет, но и 
артикулирует процедуру размежевания между «эмпирическим субъектом» (объект среди других объектов этого уже предзаданного мира, естественного мира, мира опыта) и субъектом «трансцендентальным» как «высшим основоположением синтетического знания» (автономным, воплощающим априорные, всеобщие, универсальные структуры и механизмы познавательной деятельности, пребывающим в установке cogito «с глазу на глаз» с миром в целом и конституирующим этот мир).

Далее Э. Гуссерль развивает идею о «первопорядковости» «Я»в качестве «трансцендентального субъекта»:

Я (осознающее себя как «трансцендентальное еgо») в своей конститутивной жизни конституирует все, что когда-либо оказывается для меня объективным, - как Я, которому принадлежат все конституции, которое существует в своих актуальных и потенциальных переживаниях и в свойственных ему хабитуальностях и которое конституирует в них не только всякую объективность, но и само себя как тождественное ego [6, с. 198].

Внутри конституированного в своей целостности мира осуществляется восприятие себя, в смысле личного человеческого Я, как «погруженного в мир». Осуществляется также многоуровневая конституция бытийного смысла «объективного мира» на основе «моего первопорядкового мира», выход из «первопорядковой трансцендентности» к вторичной «объективной трансцендентности» через опыт (см.: [6, с. 209-210]). Создается «универсальная смысловая надстройка» («мирообразующий смысл») над моим первопорядковым миром-монадой. Редуцированный в процедуре «эпохе» мир обнаруживается как «имманентная трансцендентность». Понятие «имманентная трансцендентность» наиболее важное для «новой онтологии», им часто обозначается само Я в его изначальности, самостоянии, «радикальном авторстве». Гуссерль своеобразно «онтологизирует» опыт: «особенностью трансцендентального феномена мира является его непосредственная данность в согласованном опыте» [6, с. 191].

Именно в феноменологической традиции оформляются контуры «новой онтологии», в том числе и как новые «условия возможности» размышления о мире и человеке, новое «рамочное соглашение», точнее «горизонтное соглашение» о преодолении субъект-объектной дихотомии, о новом, но отнюдь не беспроблемном синтезе онтологии, феноменологии, гносеологии, экзистенциально-антропологического вопрошания. Условно говоря, на пути от Канта до Гуссерля логический «трансцендентальный субъект» обретает измерение историчности (уже у Ге- 
геля как своей собственной логической истории, далее все ближе к «живой конкретной истории», к примеру, у Виндельбанда и Дильтея).

У самого Гуссерля - это темпоральная по преимуществу историяпроцессуальность опыта смыслоконституирования в актах сознания, а в поздних работах - и «историческое априори». У Хайдеггера это «фактичность» со своей собственной герменевтикой и аналитикой «вот-бытия», у Щюца - это «смысловая история», у Гадамера - «действенно-историческое сознание», у Бурдье - «историческая трансцендентность» и т.д. И это вовсе не откат маятника в сторону «эмпирического субъекта» и «естественного мира». Размежевание с эмпиризмом и эмпирическим психологизмом в понимании Я и с «естественной установкой» становится все более осознанным и детально, процедурно, методически глубоко продуманным. Речь идет о новом измерении опыта как опыта сознания, конституирующего себя и мир. Его предельно трудно, почти невозможно выразить, артикулировать поскольку в таком измерении происходит радикальное, чуть ли не роковое для ясности и прозрачности мысли совпадение выражаемого и выражающего.

Вслед за Я.А.Слининым подчеркнем еще одно коренное свойство «трансцендентальной субъективности». Признавая наличие универсальных сторон существования, качеств, механизмов организации «трансцендентального субъекта», современный российский философ обращает внимание на то, что «всякий трансцендентальный субъект представляет собой личность. Это означает, что каждый трансцендентальный субъект имеет свои неповторимые индивидуальные особенности, свою, так сказать, „интимную“ сторону существования» [16, с. 80]. И в этом смысле можно говорить не только о трансцендентальной субъективности, но и о «трансцендентальной персональности» - ситуационно-историчной, уникальной, единственной, интимной.

В этой точке мы «подключаемся» к современным постановкам вопроса о феномене «персональности». Как подчеркивают Н.С. Плотников и А.И.Хаардт, инициаторы тематического исследовательского проекта «Философские концепты „персональности“ в истории руссконемецких культурных связей»: «семантическое поле персональности и спектр составляющих его понятий образуют одну из ключевых тем философской рефлексии современности» $[13$, с. 8].

В данном случае мы фиксируем наложение семантических полей «персональности» и «трансцендентальной субъективности/трансцендентальной эгологии». Модель персональности, учитывающая условия своей возможности (в том числе, конкретно-исторические, уникальнобиографические), может быть обозначена как саморефлексивная мо- 
дель персональности. Так, к примеру, Р. Гольдт делает саморефлексивную модель персональности теоретической основой размышлений над спецификой моделей автора в автобиографии (см.: [5]). Он же высказывает мысль и о «прафеномене персонального» или «элементарных структурах персональности», подразумевая под этим создание в опыте самостановления собственной пространственно-временной системы координат, индивидуальных образов пространства-времени, собственной метафорически-ассоциативной картины мира.

«Я-трансцендентальное», «я-первопорядковое», «я-историчное» позиционирование человека по отношению к миру, которое в разных вариантах отстаивали в XX веке М. Хайдеггер, М. Шелер, Х. Плесснер, К. Ясперс, Х.-Г. Гадамер, О. Больнов, Г. Шпет, М. Бахтин и др., позволяет не только теоретически определить, но и феноменологически описать «радикальное авторство человека», его «центричность», соединенную с «экс-центричностью», возможность совершать «прорыв» к миру, к Богу, к трансцендентному. В таком контексте философия это феноменология, «человеческое дело», «последнее выговаривание и последний спор человека, захватывающие его целиком» [19, с. 330].

Осмысливая эту переориентацию современной философии в хайдеггеровском духе, В.Г. Табачковский подчеркивал, что философия становится феноменологией человеческого бытия, она выясняет его онтологические параметры, а именно - условия, благодаря которым «человеческая экзистенция» может быть тем, чем она есть [18, с. 74]. Одна из главных трудностей в осуществлении такого онтологически-антропологически-феноменологического философствования - очевидность, обманчивая простота его предмета. На это указывает, в частности, Е.К.Быстрицкий: «факт онтологической предпосланности человеческого существования в мире в силу своей очевидности и всеобщности принимается без всякого вопрошания» (см. [3, с. 114]).

Предлагая свой проект «экзистенциальной социальной онтологии» М.Н. Верников также подчеркивает «первопорядковость» человека. Так, в работе «Общество глазами конкретного человека: экзистенциальная социальная онтология» он отмечает: «на место формулы „человек является функцией общества“" выдвигается противоположная ей: „общество является функцией человека“» [4, с. 27]. Концептуальный поворот к «экзистенциальной социальной онтологии» является выражением радикального поворота, как минимум в истории западного мира, к другому типу общества.

М.Н. Верников вводит новый фундаментальный критерий для определения характера общества и исторических типов культуры: соо- 
тношение индивида и социума. В связи с этим он различает два основных типа: социоинтентное (ориентированное на общество, коллектив, всеобщее) и гомоинтентное (ориентированное на человека) общества. Радикальный социально-исторический поворот, который обозначился со второй половины XIX века, определяется как переход от доминировавшего в истории социоинтентного типа социума к гомоинтентному. Экзистенциальная онтология рассматривается, как теоретическая попытка осмыслить эту коренную трансформацию. Такая онтология оформляется как социально-философская теория, исходящая из принципа гомоинтентности общества и изучает социальное сквозь призму индивидуального человеческого существования, «глазами конкретного человека» (см.: [4, с. 33-34]).

М.Н. Верников подчеркивает, что онтологический поворот, который мы фиксируем на мировоззренческо-теоретическом уровне, является характеристикой самого современного общества, современной социокультурной ситуации. Поворот к гомоинтентному типу общества сначала проявил себя в разных формах общественного сознания - в литературе, философии, в гуманитаристике в целом. Далее он начинает захватывать и социальную практику, получая нормативно-правовое, институциональное выражение, различным образом оформляя идею самоценности человека, его права на жизнь и т.д.

Проект «экзистенциальной социальной онтологии» М.Н. Верникова не получил достаточно детальных конкретизации и текстуального оформления для того, чтобы иметь возможность говорить о нем как о концепции. Однако и в форме наброска, предложения, интеллектуального вызова он органично входит в контекст «онтологического» поворота, который осуществляется в украинской философии с конца $60-\mathrm{x}$ годов прошлого века. Сегодня, уже на определенной временной и поколенческой дистанции, мы можем подумать о том, чтобы представить эти поворотные вехи в их полноте, богатстве, полифоничности. Однако такая задача вовсе не означает простого архивирования, «музеифицирования». Драматический и трагический опыт поколения, к которому принадлежит Марат Николаевич Верников, должен стать частью живой традиции, которая не прерывается...

\section{Литература}

[1] Аляєе Г.Є. Філософський універсум С.Л. Франка. Персоналістична метафізика всеєдності в горизонтах нової онтології ХХ ст. - 
К. : ПАРАПАН, 2002.

[2] Балей C. Зібрання праць: У 5 т. [у 2 кн.] / О.В. Чайковський (відп. ред.), М.М. Верников (наук.-пошук. робота, укладання, заг. ред., теор. аналіз праць). - Т. II. - Львів : Вид-во національного ун-ту «Львівська політехніка», 2009.

[3] Бъстрицкий Е.К. Феномен личности: мировоззрение, культура, бытие. - К. : Наукова думка, 1991.

[4] Верніков M.M. Суспільство очима конкретної людини: екзистенціальна соціальна онтологія // Філософські пошуки. Вип. XVIIXVIII. - Львів-Одеса : Cogito-Центр Європи, 2004. - C. 26-47.

[5] Голъдm P. Модели личности автора в автобиографии и дневнике // Персональность. Язык философии в русско-немецком диалоге / Под ред. Н.С. Плотникова и А.И. Хаардта при участии В.И. Молчанова. - М. : Модест Колеров, 2007. - С. 307-325.

[6] Гуссерль Э. Картезианские размышления. - СПб. : Наука-Ювента, 1998.

[7] Малахов B.A. Постонтология, или как возможна философия Духа // Малахов В.А. Уязвимость любви. - К. : Дух і Літера, 2005. C. 51-58.

[8] Мінаков М.А. Історія поняття досвіду. - К. : ПАРАПАН, 2007.

[9] Мировоззренческая культура личности: (Философские проблемы формирования) / В.П. Иванов, Е.К. Быстрицкий, Н.Ф. Тарасенко, В.П. Козловский; Отв. ред. В.П. Иванов. - К. : Наукова думка, 1986.

[10] Нікіборова I. Мова антропологічної рефлексії у сучасній українській філософії: концепція В.Г. Табачковського // Наукове пізнання: методологія та технологія. Філософія - 2011. - № 1(26). C. 68-72.

[11] Нікіфорова I. Антропологічна рефлексія в сучасній українській філософії // Наукові записки Київського університету туризму, економіки і права. Серія: філософські науки / Гол. ред. В.С. Пазенок. - К. : КУТЕП, 2011. - Вип. 11.- С. 295-308. 
[12] Посвящения Марату. Сборник статей памяти Марата Николаевича Верникова / Сост. Л.Н. Богатая, С.М. Повторева. - Одесса : Печатний дом, 2012.

[13] Персональность. Язык философии в русско-немецком диалоге / Под ред. Н.С.Плотникова и А.И. Хаардта при участии В.И. Молчанова. - М. : Модест Колеров, 2007.

[14] Пролеев С.В. Духовность и бытие человека / Отв. ред. Е.К. Быстрицкий. - К. : Наукова думка, 1992.

[15] Рубинштейн С.Л. Человек и мир // Рубинштейн С.Л. Проблемы общей психологии. - М., 1976. - С. 253-382.

[16] Слинин Я.А. Трансцендентальный субъект: феноменологическое исследование. - М. : Наука, 2001.

[17] Табачковсъкий В.Г. В пошуках невтраченого часу: Нариси про творчу спадщину українських філософів-шестидесятників. - K. : ПАРАПАН, 2002.

[18] Табачковсъкий В.Г. Полісутнісне Номо: Філософсько-мистецька думка в пошуках «неевклидової рефлективності». - К. : ПАРАПАН, 2005.

[19] Хайдеггер M. Основные понятия метафизики // Хайдеггер М. Время и бытие: Статьи и выступления. - М. : Республика, 1993. - C. 327-346.

[20] Щюи, А. Избранное: Мир, светящийся смыслом. - М. : Российская политическая энциклопедия, 2004.

Надійшла до редакиії 12 березня 2013 р. 